Vol 13, Issue 8, 2020

\title{
SOCIODEMOGRAPHIC AND COMORBIDITY PROFILES OF MIGRAINE PATIENTS: AN OUTPATIENT-BASED STUDY IN A TERTIARY CARE HOSPITAL
}

\author{
MUDDASIR BANDAY ${ }^{*}$, MAQBOOL WANI' ${ }^{2}$, UMER FAROOQ ${ }^{3}$, BILAL PARRA ${ }^{4}$, YOUNIS RATHER ${ }^{5}$ \\ ${ }^{1}$ Department of Clinical Pharmacology, Sheri Kashmir Institute of Medical Sciences, Srinagar, Jammu and Kashmir, India. ${ }^{2}$ Department \\ of Neurology, Sheri Kashmir Institute of Medical Sciences, Srinagar, Jammu and Kashmir, India. ${ }^{3}$ Department of Neurology, \\ Government Medical College, Srinagar, Jammu and Kashmir, India. ${ }^{4}$ Department of Statistics, Government Degree College, Anantnag, \\ Jammu and Kashmir, India. ${ }^{5}$ Department of Pharmacology, Government Medical College, Srinagar, Jammu and Kashmir, India. \\ Email: banday. muddasir@gmail.com
}

Received: 06 April 2020, Revised and Accepted: 16 May 2020

ABSTRACT

Objective: Migraine is a primary headache disorder. The study was undertaken to assess correlation between sociodemographic characteristics of migraineurs with their various comorbidities so as to determine most important factors influencing their comorbidity profile.

Methods: A prospective study was conducted between June 2018 -April 2020 in 323 patients suffering from migraine in out-patient department of Neurology. Patients were labeled as migraine on the basis of Simplified Diagnostic Criteria for Migraine. A structured questionnaire was used for evaluation of sociodemographic variables and evidence based approach was adapted to fill psychiatric and comorbidity profiles of patients.

Results: In 323 patients of migraine males were 30 (9.3\%) and females 293 (90.7\%). Mean age of males is $38.80 \pm 17.53$ years and of females $35.38 \pm 13.29$ years, $(p=0.307)$. Most of them were in 21-30 years age group followed by 31-40 years Majority of patients were from district Srinagar followed by Ganderbal. Housewives formed major group of patients followed by students It was seen more in the illiterate class than in literates. 57\% patients belonged to lower middle class. Psychiatric comorbidities including anxiety,depression and physical comorbidities like hypertension, hypothyroidism and comorbid pains were common associations. Comorbidities have been compared with mean age of the patients and it was found that psychiatric comorbidities, neuropathic pain, hypothyroidism, hypertension, Type 2 DM, comorbid pains and PCOD were statistically significant, $(\mathrm{p}=\leq 0.05)$

Conclusion: Most common comorbidities associated with migraine are anxiety, depression, neuropathic pain, hypothyroidism, hypertension, Type $2 \mathrm{DM}$ and comorbid pain. Comorbidities have direct impact on nature of treatment protocol and need to be addressed to achieve outcome based treatment.

Keywords: Migraine, Comorbidities, Sociodemography.

(c) 2020 The Authors. Published by Innovare Academic Sciences Pvt Ltd. This is an open access article under the CC BY license (http://creativecommons. org/licenses/by/4. 0/) DOI: http://dx.doi.org/10.22159/ajpcr.2020.v13i8.38054

\section{INTRODUCTION}

Migraine is a primary headache disorder. It is the second most common painful and debilitating disorder in the world, afflicts approximately $15 \%$ of women and $6 \%$ of men over a 1 year period [1]. It has a global prevalence of around one in seven people [2]. According to the Global Burden of Disease Study, it ranks as the seventh most common cause of disability worldwide, rising to the most common cause in the age of under 50 [3]. Migraine is an important cause of reduced health-related quality of life and has a significant and negative personal, societal, and economic burden and is often underdiagnosed, misdiagnosed (e.g., in sinusitis), and undertreated in both primary and secondary care [4-8]. The latest version of the International Headache society's International Classification of Headache disorders ICHD - III (beta) (Headache Classification Committee of the International headache Society, 2013) [9] classifies migraine as (i) migraine without aura, (ii) migraine with aura, (iii) chronic migraine, (iv) complications of migraine, (v) probable migraine, and (vi) episodic syndrome that may be associated with migraine. A simplified diagnostic criterion for migraine is quite reproducible which mentions as repeated attacks of headache lasting 4-17 h in patients with a normal physical examination, no other reasonable cause for the headache and at least 2 of these features as (i) unilateral pain, (ii) throbbing pain, (iii) aggravation by movement, and (iv) moderate or severe intensity plus at least one of the features such as nausea/vomiting, photophobia, and phonophobia [1]. There are several disorders that are commonly comorbid with migraine.
Among the most common are anxiety, chronic pain, fibromyalgia, bipolar disorder, cardiovascular diseases, epilepsy, hypertension, headache (other than migraine), irritable bowel syndrome, sleep disorders, obesity, and GERD [10]. The present study, therefore, aims to provide insight into the prevalence of comorbidities in patients with episodic and chronic migraine in our ethnic population. Despite a better understanding of global migraine prevalence, the influence of sociodemographic factors has not been completely characterized. We need to understand how migraine fluctuates as a function of age, sex, race, ethnicity, socioeconomic status, occupation, exercise habits, and relevant family history. Hence, we planned this study to better understand the distribution and burden of migraine and help to define and identify the groups at greatest risk for developing the disorder [11]. Moreover, the study was also undertaken to assess the correlation between sociodemographic characteristics of migraineurs with their various comorbidities so as to determine the most important factors influencing their comorbidity profile.

\section{METHODS}

A prospective study was conducted between June 2018 and April 2020 in 323 patients suffering from migraines in the outpatient department of neurology. The study received approval from the Institutional Ethics Committee. Patients were labeled as migraines on the basis of Simplified Diagnostic Criteria for Migraine adapted from the International Headache Society Classification (Headache Classification Committee of the 
International Headache Society 2013). Patients were enrolled in the study after informed written consent. A structured self-designed questionnaire was used to interview the patients clinically diagnosed as migraines for evaluation of sociodemographic variables including age, gender, marital status, residence, education, occupation, and socioeconomic status. The social stratification was determined using Modified Kappuswamy's scale: Recalculated Family Income groups of the Kappuswamy's scale as of 2014 [12]. The evidence-based approach was adapted to fill the comorbidity profile of the patients. Diagnosis of associated psychiatric and physical comorbidities was done on the basis of history, clinical examination, and relevant investigation. Psychiatric comorbidities such as anxiety and its severity were measured using the Hamilton Anxiety Rating Scale (HAM-A). Psychiatric comorbidities like anxiety and depression was measured using Hamilton Anxiety Rating Scale (HAM-A) and Hamilton Depression Rating Scale (HAM-D) respectively. Generalized Anxiety Disorder by (GAD-7) scale. Mood disorders by Bipolar Spectrum Diagnostic Scale (BSDS). Subjects were diagnosed as diabetes mellitus according to the diagnostic criteria of the American Diabetes Association. Study subjects were diagnosed as a case of hypertension [13] and obesity [14] according to the standard diagnostic criteria. Detailed clinical history was taken in all patients and a clinical examination with specific reference to central nervous system (CNS) examination such as Romberg's sign, tandem gait, drift of outstretched hands, finger-nose test, finger dexterity, binocular visual fields, to confrontation, eye movements, facial weakness, pupillary responses and Horner's syndrome, tendon reflexes and plantar responses, and fundoscopy was carried out. Investigations such as CT head and MRI brain was advised in some patients who did not respond to the initial treatment. The Statistical Package for the Social Sciences program was used for statistical analysis (SPSS Inc. Chicago IL-USA). A univariate statistical analysis was conducted using Fisher's exact test to assess the association between comorbidities versus sociodemographic characteristics. Independent t-test was used to compare comorbidities with mean age groups with a significance level of $\mathrm{p} \leq 0.05$. Results were given as mean $\pm \mathrm{SD}$

\section{RESULTS}

The study included 323 patients of migraine among which males were $30(9.3 \%)$ and females were $293(90.7 \%)$. The mean age of males is $38.80 \pm 17.53$ years and of females $35.38 \pm 13.29$ years, with a $p=0.307$. Most of them were in the 21-30 years age group (26\%), followed by 31-40 years $(24.45 \%)$. The majority of patients were from district Srinagar (36.53\%) followed by district Ganderbal (14.24\%) (Table 1).

On the basis of occupation, housewives formed the major group of patients $(56 \%)$ followed by students $(25.2 \%)$, government employees $(8.9 \%)$, laborers $(4 \%)$, businessmen $(4.5 \%)$, and farmers $(1.3 \%)$. On the basis of education status, it was seen more in the illiterate class 196 $(60.68 \%)$ than in literates 127 (39.31\%). As regards the socioeconomic status, migraine was seen more in the lower middle class of the society (57\%) (Table 2).

The distribution of various comorbidities in migraine patients is depicted in Table 3. Psychiatric comorbidities mainly include anxiety

Table 1: District-wise distribution of migraine patients

\begin{tabular}{lll}
\hline District & Frequency $(\mathbf{n = 3 2 3})$ & Percentage \\
\hline Bandipora & 16 & 4.9 \\
Kupwara & 21 & 6.5 \\
Ganderbal & 46 & 14.24 \\
Pulwama & 38 & 11.76 \\
Baramulla & 34 & 10.52 \\
Anantnag & 15 & 4.64 \\
Handwara & 2 & 0.92 \\
Budgam & 28 & 8.66 \\
Srinagar & 118 & 36.53 \\
Kulgam & 2 & 0.619 \\
Kashtwar & 2 & 0.619 \\
Total & 323 & 100.0 \\
\hline
\end{tabular}

(13.3\%) and depression $(11.5 \%)$ as common associations with migraine. Among the physical comorbidities, hypertension (12.4\%), hypothyroidism (9.9\%), and comorbid pains (low backache, cervical spondylosis, and fibromyalgia) (9.9\%) are commonly associated with migraine patients.

All comorbidities have been compared with a mean age of the patients and it was found that psychiatric comorbidities (anxiety and depression), neuropathic pain, hypothyroidism, hypertension, type 2 Diabetes mellitus, comorbid pain, and PCOD were statistically significant ( $\mathrm{p} \leq 0.05$ was considered statistically significant) (Table 4).

In drawing a relationship between various comorbidities and the educational status of the patients, it was observed that hypothyroidism, hypertension, comorbid pains (LBA, cervical spondylosis, and fibromyalgia), and PCOD showed preponderance for the illiterate patients and $\mathrm{p}$ values for these comorbidities were statistically significant $(\mathrm{p} \leq 0.05)$ (Table 5).

No statistically significant relation was observed between comorbidities and gender of the patients; likewise, with regard to socioeconomic status, none of the comorbidity showed a predilection for any particular class of patients.

\section{DISCUSSION}

The present study observed that in our ethnic population, females outnumber males with a ratio of around 9:1. The mean age of males was $38.80 \pm 17.53$ years and females $35.38 \pm 13.29$ years. The maximum number of patients both men and women belonged to the age interval of 21-30 years followed by 31-40 years. Our study commensurate with the work conducted by Lipton et al., where the migraine was highest in those aged 30-39 years for both men (7.4\%) and women (24.4\%).

Table 2: Distribution on the basis of socioeconomic status

\begin{tabular}{lll}
\hline Class & Frequency $(\mathbf{n = 3 2 3})$ & Percentage \\
\hline Upper class & 10 & 3.09 \\
Upper middle class & 73 & 22.60 \\
Lower middle class & 184 & 56.96 \\
Upper lower class & 9 & 2.7 \\
Lower class & 47 & 14.55 \\
Total & 323 & 100.0 \\
\hline
\end{tabular}

Table 3: Percentage of various comorbidities observed in the study

\begin{tabular}{|c|c|c|}
\hline Comorbidity & $\begin{array}{l}\text { Frequency out } \\
\text { of }(n=323)\end{array}$ & $\begin{array}{l}\text { Percentage } \\
\text { out of } 323\end{array}$ \\
\hline Anxiety & 43 & 13.3 \\
\hline Depression & 37 & 11.5 \\
\hline BPAD & 4 & 1.2 \\
\hline Seizure disorder & 7 & 2.2 \\
\hline Vertigo & 9 & 2.8 \\
\hline Neuropathic pain & 6 & 1.9 \\
\hline Hypothyroidism & 32 & 9.9 \\
\hline HTN & 40 & 12.4 \\
\hline Palpitations & 12 & 3.7 \\
\hline T2DM & 7 & 2.2 \\
\hline IBS & 3 & 0.9 \\
\hline APD & 12 & 3.7 \\
\hline Asthma & 2 & 0.6 \\
\hline Obesity & 1 & 0.3 \\
\hline $\begin{array}{l}\text { LBA, Cervical spondylosis, } \\
\text { fibromyalgia }\end{array}$ & 32 & 9.9 \\
\hline PCOD & 8 & 2.5 \\
\hline
\end{tabular}

BPAD: Bipolar affective disorder, HTN: Hypertension, T2DM: Type 2 diabetes mellitus, IBS: Irritable bowel syndrome, APD: Acid peptic dyspepsia, LBA: Low backache, PCOD: Polycystic ovarian disorder 
Table 4: Comparison between the presence and absence of comorbidities with a mean age

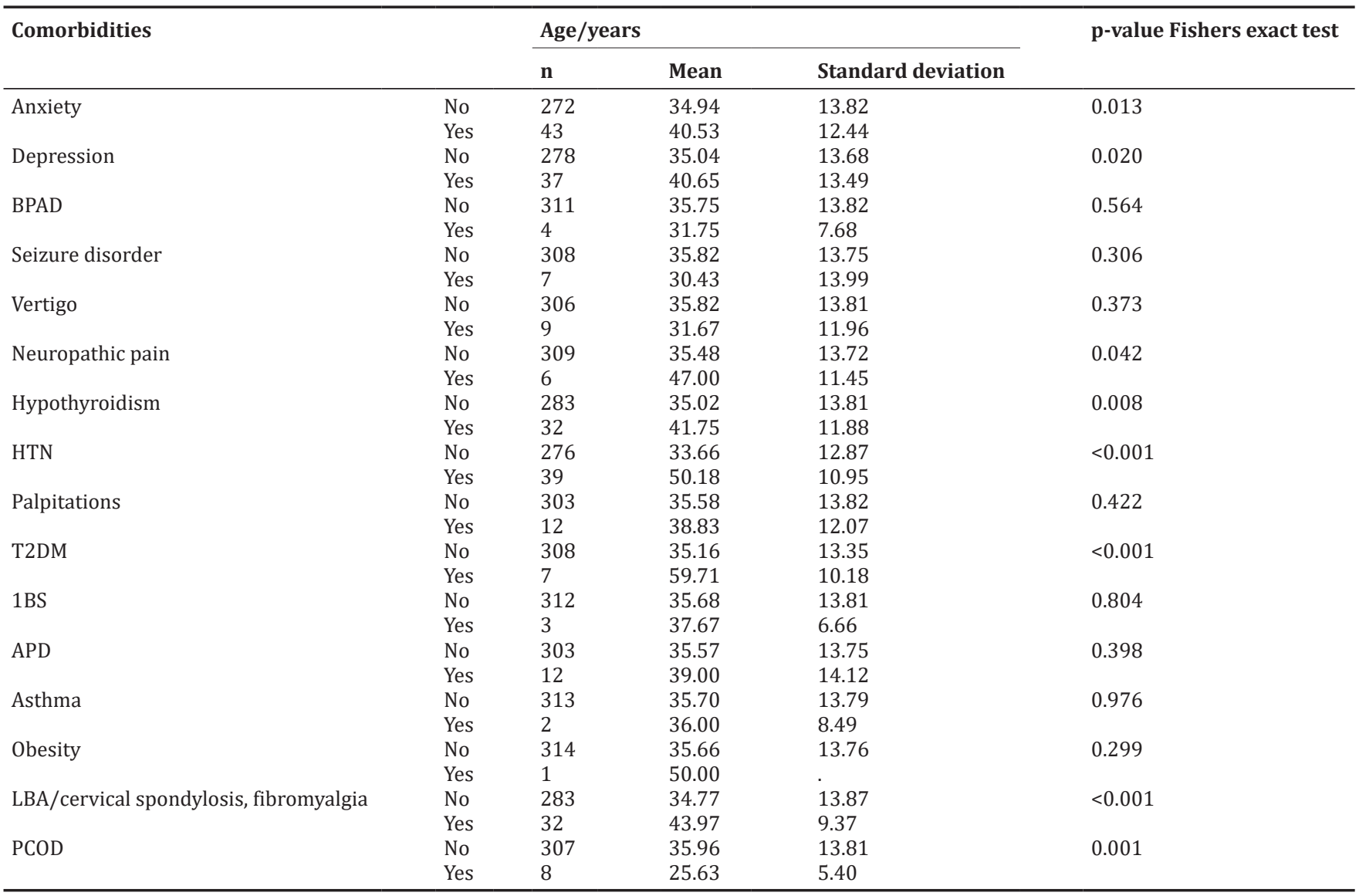

* Results are given as Mean \pm SD. Independent T-test was used to compare groups with a significance level of $\mathrm{p} \leq 0.05$.

Prevalence was lowest in those aged 60 years or older at $1.6 \%$ in men and $5.0 \%$ in women. At the other end of the lifespan, the prevalence was $4.0 \%$ in men and $6.4 \%$ in women aged between 12 and 17 years [4]. Our study is also consistent with the findings of Koseogu et al. [15].

In one of the American migraine study Surveys (AMSS) and in other studies employing a variety of methodologies, migraine was about 3 times more common in females than in males [16]. On the contrary, in our study, it was found 9 times more in females than males. In a study conducted by Hossain et al., it was observed that most of the migraineurs were females (72.7\%) and housewives (57.6\%) [17].

Our study also confirmed that housewives formed a major group of patients $(56 \%)$. The sex difference can be explained on the basis of hormonal fluctuations in females. In spite of this explanation, the preponderance is observed in postmenopausal females which circulating hormones cannot explain. In our study, it was observed that maximum migraine patients belonged to lower middle class (56.96\%). This finding is similar to the American Migraine Study [18], where migraine was found more prevalent in lower-income groups compared with higher income groups. Similar results have been obtained in other US studies using either income or education as indicator or measure of socioeconomic status $[19,20]$. This inverse relationship between disease prevalence and socioeconomic status may be accounted for by social causation or social selection [21]. According to Lipton et al., this inverse relationship between migraine and socioeconomic status has not been confirmed in studies outside the US [22,23], but in our ethnic population majority of patients were from lower socioeconomic groups. Our study also aims to observe the frequency of different common psychiatric and physical comorbidities in migraine patients. It was observed that patients had a significantly higher risk of anxiety disorder $(p=0.013)$, depression $(p=0.02)$, neuropathic pain $(p=0.042)$, hypothyroidism $(\mathrm{p}=0.008)$, hypertension $(\mathrm{p}<0.008)$ and type 2DM $(\mathrm{p}<0.001)$, comorbid pains $(\mathrm{p}<0.001)$, and PCOD $(\mathrm{p}<0.001)$.

Findings from a study conducted in Taiwan shows that migraine was associated with a significantly higher risk of an anxiety disorder $(\mathrm{RR}=2.89,95 \% \mathrm{CI}=2.37-3.52)$ and depression $(\mathrm{RR}=3.83,95 \% \mathrm{CI}=3.14-$ 4.68) than the non-migraineurs [24]. Breslan et al. [25] found that patients with migraines were predisposed to an increased risk of depression $(\mathrm{OR}=5.8)$ and patients with depression were at higher risk of developing migraines ( $\mathrm{OR}=3.4)$.The American Migraine Prevalence and Prevention (AMPP) study showed that patients with migraines were more likely to suffer from anxiety $(\mathrm{OR}=1.8)$, depression $(\mathrm{OR}=2.0)$, and bipolar disorders [26].

In clinical and community-based studies, the association between anxiety and migraine has been noted [27]. Mc Williams et al. [28], in a study, showed the association between migraine and anxiety: $9.1 \%$ of subjects with migraine have a generalized anxiety disorder, compared to $2.5 \%$ without migraine. Finding from our study and the aforementioned studies indicated that the relationship between depression and migraine appears to be bidirectional, where one disease entity increases the risk of the development of the other and vice versa. Results from the present study confirmed that psychiatric disorders, especially anxiety and depression, have a greater likelihood to coexist with migraines. Our study found no significant link between migraine sufferers and BPAD.

With regard to metabolic syndrome, a study by Yong et al. [24] observed that migraineurs have an increased risk of hypertension ( $R R=1.64,95 \%$ $\mathrm{CI}=1.35-1.99)$ than non-migraineurs. Scher et al. [29] also reported an increased risk of hypertension $(\mathrm{OR}=1.63,95 \% \mathrm{CI}=1.2=2.1$ ). These studies are similar to our study which revealed a significant association 
Table 5: Comparison between the presence and absence of comorbidities with educational status

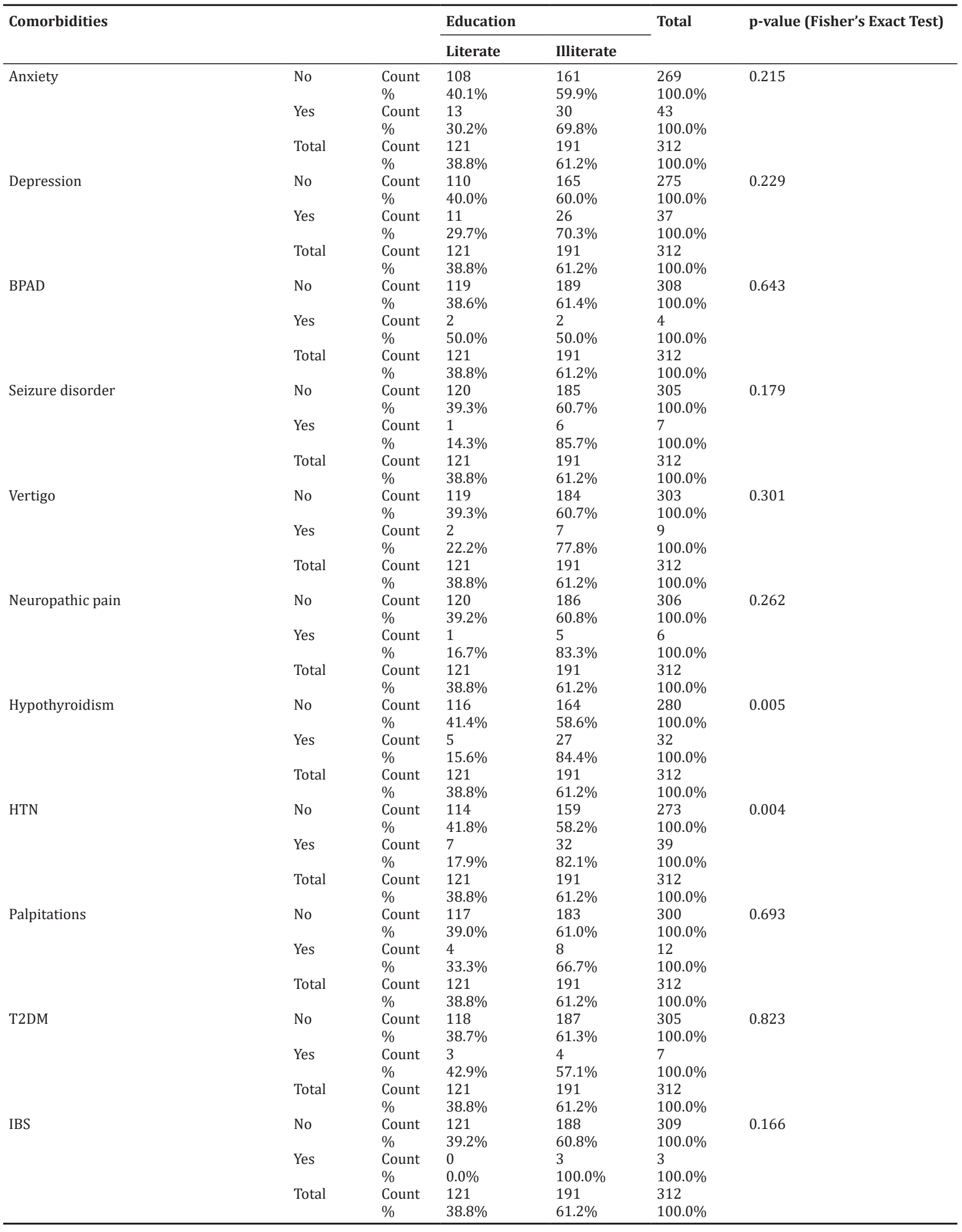


Table 5: (Continued)

\begin{tabular}{|c|c|c|c|c|c|c|}
\hline \multirow[t]{2}{*}{ Comorbidities } & & & \multicolumn{2}{|c|}{ Education } & \multirow[t]{2}{*}{ Total } & \multirow[t]{2}{*}{ p-value (Fisher's Exact Test) } \\
\hline & & & Literate & Illiterate & & \\
\hline \multirow[t]{5}{*}{ APD } & No & Count & 117 & 183 & 300 & 0.693 \\
\hline & Yes & Count & 4 & 8 & 12 & \\
\hline & & $\%$ & $33.3 \%$ & $66.7 \%$ & $100.0 \%$ & \\
\hline & Total & Count & 121 & 191 & 312 & \\
\hline & & $\%$ & $38.8 \%$ & $61.2 \%$ & $100.0 \%$ & \\
\hline \multirow[t]{6}{*}{ Asthma } & No & Count & 121 & 189 & 310 & 0.259 \\
\hline & & $\%$ & $39.0 \%$ & $61.0 \%$ & $100.0 \%$ & \\
\hline & Yes & Count & 0 & 2 & 2 & \\
\hline & & $\%$ & $0.0 \%$ & $100.0 \%$ & $100.0 \%$ & \\
\hline & Total & Count & 121 & 191 & 312 & \\
\hline & & $\%$ & $38.8 \%$ & $61.2 \%$ & $100.0 \%$ & \\
\hline \multirow[t]{5}{*}{ Obesity } & No & Count & 121 & 190 & 311 & 0.425 \\
\hline & & $\%$ & $38.9 \%$ & $61.1 \%$ & $100.0 \%$ & \\
\hline & Yes & Count & 0 & 1 & 1 & \\
\hline & Total & Count & 121 & 191 & 312 & \\
\hline & & $\%$ & $38.8 \%$ & $61.2 \%$ & $100.0 \%$ & \\
\hline \multirow[t]{6}{*}{ LBA, cervical spondylosis, fibromyalgia } & No & Count & 118 & 162 & 280 & $<0.001$ \\
\hline & & $\%$ & $42.1 \%$ & $57.9 \%$ & $100.0 \%$ & \\
\hline & Yes & Count & 3 & 29 & 32 & \\
\hline & & $\%$ & $9.4 \%$ & $90.6 \%$ & $100.0 \%$ & \\
\hline & Total & Count & 121 & 191 & 312 & \\
\hline & & $\%$ & $38.8 \%$ & $61.2 \%$ & $100.0 \%$ & \\
\hline \multirow[t]{6}{*}{ PCOD } & No & Count & 115 & 189 & 304 & 0.033 \\
\hline & & $\%$ & $37.8 \%$ & $62.2 \%$ & $100.0 \%$ & \\
\hline & Yes & Count & 6 & 2 & 8 & \\
\hline & & $\%$ & $75.0 \%$ & $25.0 \%$ & $100.0 \%$ & \\
\hline & Total & Count & 121 & 191 & 312 & \\
\hline & & $\%$ & $38.8 \%$ & $61.2 \%$ & $100.0 \%$ & \\
\hline
\end{tabular}

between migraine and hypertension. In addition to hypertension, our study goes further and observed physical comorbidities such as Type 2 DM, hypothyroidism, comorbid pains (cervical spondylosis, LBA, and fibromyalgia), and PCOD are more associated with migraine sufferers. This can possibly be explained on the basis that our ethnic population has a high prevalence and burden of these ailments. An AMPP study conducted by Buse et al. [26] reported that in addition to lower socioeconomic status, migraine patients were more likely to have heart diseases $(\mathrm{OR}=1.4)$, respiratory diseases such as allergies, asthma, sinusitis, bronchitis, and COPD (OR=1.4-2.0), and obesity $(\mathrm{OR}=1.2-1.5)$. In contrast to the report by Buse et al., our results did not show any association between migraine and heart diseases, respiratory disorders, and obesity.

\section{CONCLUSION}

The present study suggested the higher prevalence of migraines in a lower socioeconomic group of society. The most common comorbidities associated with migraine are anxiety, depression, neuropathic pain, hypothyroidism, hypertension, Type 2 DM, and comorbid pain. These comorbid conditions have an implication in formulating preventive treatment protocols of the patients. The presence of comorbidities alters the nature, progression, and response to treatment in view of polytherapy and expected drug interactions and adverse drug reactions, so these comorbidities need to be addressed simultaneously to achieve outcomebased treatment, thereby improving compliance and quality of life.

\section{AUTHORS CONTRIBUTION}

Muddasir Banday article conception designed the study and prepared the manuscript, Maqbool Wani and Umer Farooq carried out the clinical work, Bilal Parra performed the statistical analysis and data management, and Younis Rather reference research. All authors read and approved the final manuscript.

\section{CONFLICTS OF INTEREST}

All authors declare no potential conflicts of interest.

\section{AUTHORS' FUNDING}

There was no financial support from any funding agency.

\section{REFERENCES}

1. Peter JG, Neil HR. Migraine and other primary headache disorders In: Dennis LK, Anthony SF, Stephen LH, Dan LL, Larry J, Joseph L, editors. Harrison's Principles of Internal Medicine. United States: McGraw Hill; 2016. p. 2586-98.

2. Steiner TJ, Stovner LJ, Birbeck GL. Migraine: The seventh disabler. J Headache Pain 2013;14:1.

3. Steiner TJ, Stovner LJ, Vos T. GBD 2015: Migraine is the third cause of disability in under 50s. J Headache Pain 2016;17:104.

4. Lipton RB, Bigal ME, Diamond M, Freitag F, Reed ML, Stewart WF. Migraine prevalence, disease burden, and the need for preventive therapy. Neurology 2007;68:343-9.

5. Hawkins K, Wang S, Rupnow M. Direct cost burden among insured US employees with migraine. Headache 2008;48:553-63.

6. Vos T, Flaxman AD, Naghavi M, Lozano R, Michaud C, Ezzati M, et al. Years lived with disability (YLD) for 1160 sequelae of 289 diseases and injuries 1990-2010: A systematic analysis for the global burden of disease study 2010. Lancet 2012;380:2163-96.

7. Blumenfeld AM, Varon SF, Wilcox TK, Buse DC, Kawata AK, Manack A, et al. Disability, HRQoL and resource use among chroniv and episodic migraineures: Results from the international burden of migraine study (IBMS). Cephalalgia 2011;31:301-15.

8. Schreiber CP, Hutchinson S, Webster CJ, Ames M, Richardson MS, Powers C. Prevalence of migraine in patients with a history of self reported or physician diagnosed "sinus" headache. Arch Intern Med 2004; $44: 856-64$.

9. Headache Classification Committee of the International Headache society (IHS). The international classification of headache disorders, $3^{\text {rd }}$ 
edition (beta version). Cephalalgia 2013;33:629-808

10. Hepp Z, Dodick DW, Varon SF, Chia J, Matthew N, Gillard P, et al. Persistence and switching patterns of oral migraine prophylactic medications among patients with chronic migraine: A retrospective claims analysis Cephalalgia 2017;37:470-85

11. Buse DC, Manack AN, Fanning KM, Serrano D, Reed ML, Turkel CC, et al. chronic migraine prevalence, disability, and sociodemographic factors: Results from the American migraine prevalence and prevention study. Headache 2012;52:1526-41.

12. Singh T, Sharma S, Nagesh S. Socioeconomic status scales updated for 2017. Int J Res Med Sci 2017;7:3264-7.

13. Chobanian AV, Bakris GL, Black HR, Cushman WC, Green LA, Izzo JL, et al. The seventh report of the joint national committee on prevention, detection, evaluation and treatment of high blood pressure. JAMA 2003;289:2560-72.

14. Hanlon P, Byers M, Walker BR, Macdonald HM. Environmental and nutritional factors in disease. In: Colledge NR, Walker BR, Ralston SH, editors. Davidson's Principles and Practice of Medicine. $21^{\text {st }}$ ed. United Kingdom: Churchill Livingstone; 2010. p. 116-25.

15. Köseoglu E, Naçar M, Talaslioglu A, Cetinkaya F. Epidemiological and clinical characteristics of migraine and tension type headache in 1146 females in Kayseri, Turkey. Cephalalgia 2003;23:381-8

16. Lipton RB, Stewart WF, Diamond S, Diamond ML, Reed M. Prevalence and burden of migraine in US: Data from the American migraine study II. Headache 2001;41:646-57.

17. Hossain MA, Hakim M, Hasan M, Rahman MA, Rashid M, Sagir G, et al. Socio-demographic and comorbidity profiles of migraine patients in a headache clinic of a tertiary care hospital in Dhaka city. J Natl Inst Neurosci 2017;3:48-51.

18. Stewart WF, Lipton RB, Celentanoo DD, Reed M. Prevalence of migraine headache in United States. Relation to age, income, race and other sociodemographic factors. JAMA 1992;267:64-9.

19. Stang PE, Osterhaus JT. Imapct of migraine in the United States: Data from the national health interview survey. Headache 1993;33:29-35.

20. Stang P, Sternfiled B, Sidney S. Migraine heache in prepaid health plan: Ascertainment, demographoes, physiological and behavioural factors. Headache 1996;36:69-76.

21. Dohrenwend BP, Levav I, Shrout PE, Schwartz S, Naveh G, Link BG, et al. socioeconomic status and psychiatric disorders: The causationselection issue. Science 1992;255:946-52.

22. Launer LJ, Terwindt GM, Ferrsri MD. The prevalence and characteristics of migraine in a population cohort: The GEM study. Neurology 1999;53:537-42.

23. O'Brien B, Goeree R, Streiner D. Prevalence of migraine headaches in Canada: A population based survey. Int J Epidemiol 1994;23:1020-6.

24. Chen YC, Tang CH, Ng K, Wang SJ. Comorbidity profiles of chronic migraine sufferers in a national database in Taiwan. J Headache Pain 2012;13:311-9.

25. Breslau N, Lipton RB, Stewart WF, Schultz LR, Welch KM. Comorbidity of migraine and depression: Investigating potential etiology and prognosis. Neurology 2003;60:1308-12.

26. Buse DC, ManackA, Serrano D, Turkel C, Lipton RB. Sociodemographic and comorbidity profiles of chronic migraine and episodic migraine sufferers. J Neurol Neurosurg Psychiatry 2010;81:428-32.

27. Wang SJ, Fuh JL, Chen PK. Comorbidities of migraine. Front Neurol $2010 ; 1: 16$

28. McWilliams LA, Goodwin RD, Cox BJ. Depression and anxiety associated with three pain conditions: Results from a nationally representative sample. Pain 2004;111:77-83.

29. Scher AI, Terwindt GM, Picavet HS, Verschuren WM, Ferrari MD, Launer LJ. Cardiovascular risk factors and migraine: The GEM population-based study. Neurology 2005;64:614-20. 